\title{
Does Technique of Mesenchymal Stem Cells Perineural Migration Seem Promising in Technologies of Combined Therapy with Stem Cells?
}

\author{
Koulchitsky Stanislav ${ }^{1}$, Zamaro Aleksandra ${ }^{2}$, Navitskaya Valeria ${ }^{3}$, Shanko Yuri ${ }^{3}$ and Kulchitsky \\ Vladimir*2 \\ ${ }^{1}$ Liege University, Belgium \\ ${ }^{2}$ Brain Center, Institute of Physiology, National Academy of Sciences, Belarus \\ ${ }^{3}$ Republican Scientific and Practical Center of Neurology and Neurosurgery, Belarus \\ *Corresponding author: Kulchitsky Vladimir, Institute of Physiology, National Academy of Sciences, Belarus
}

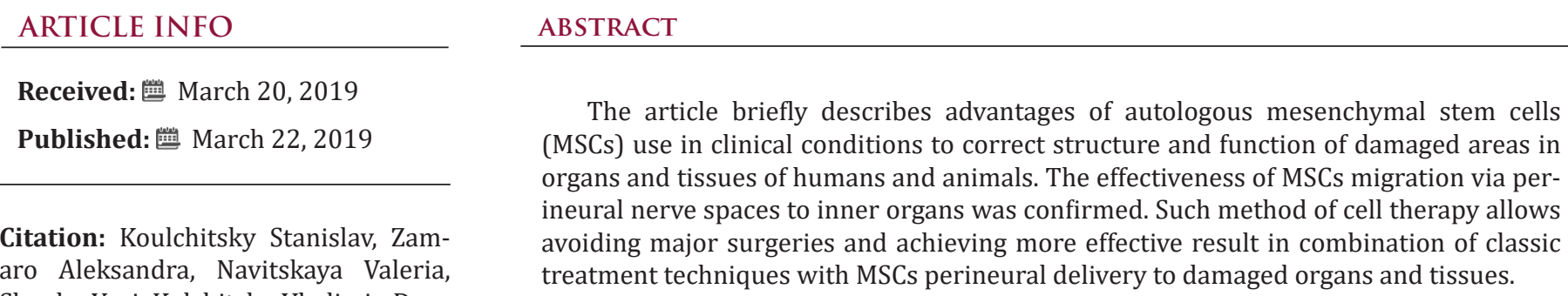

Shanko Yuri, Kulchitsky Vladimir. Does

Technique of Mesenchymal Stem Cells Perineural Migration Seem Promising in Technologies of Combined Therapy with Stem Cells?. Biomed J Sci \& Tech Res 16(2)-2019. BJSTR. MS.ID.002830.

\section{Introduction}

The progress of modern medicine is also associated with highcost technologies, expensive creation of medicines, and unique ways of transplantations of inner organs, which are available only for selected people [1]. However, statistics even in advanced countries shows low success in treatment of socially important diseases [1,2]. Mortality due to cardiovascular diseases and oncological pathology remains high. So, classis and even innovative therapeutic and surgical techniques of fatal pathological processes treatment appeared to be low-effective. All realistic people think that such situation cannot be accepted. It is fortunate that there are modern Don Quixote's who try to struggle against certain diseases using alternative ways of treatment but not against windmills. It is important that smart part of modern Don Quixote's does not reject existing protocols of treatment. They try to broaden possibilities of these methods by new ideas. Researchers create such innovative techniques which complement classic ones [3-5]. What did we really achieve till nowadays?

We will focus attention on treatment techniques using stem cells (SCs) in this article. Discovery of SCs perplexed scientists. It was found that organs and tissues have potential to recover damaged tissue areas. But why such potential appeared to be so weak? We always stare in envy at scientific films about recovery of damaged tails in lizards. But reparative processes involving endogenous SCs are low-effective in humans. Researchers tried to combine cell therapy with standard protocols of treatment-and the hope appeared on the horizon. Unfortunately, all good hopes were destroyed by data on follow-up results. First positive outcomes of such combined therapy were of short duration. SCs did not want 
to survive in tissues. That is why there were weak positive effects of cell therapy noticed in long follow-up periods. Researchers tried to improve the situation by using scaffolds, exosomes and techniques of directed SCs movement caused by magnet and ultrasound [3-5]. Also new methods of combined therapy using stem cells and macrophages were developed [1]. It was based on join role of both stem cells and macrophages in the processes of immunosuppression, tissue remodelling, angiogenesis [1].

\section{Advantages of Perineural Way of Autologous MSCs Injection for Recovery of Impaired Functions of Human Tissues and Organs}

Authors enthusiastically began experimental analysis of MSCs functions in the recovery of impaired brain functions [6-10] Majority of scientists apply systemic ways of MSCs administration, but this leads to inconsistent results and does not satisfy neither patients, nor doctors. The problem of blood-brain barrier overcome is still unresolved. Its protective function is amazing - take at least observation when post mortal injection of trypan blue into brain major vessels does not allow identifying this stain in brain tissue within several hours [11]. Administration of MSCs via lumbar puncture does not consider rostro-caudal flow of cerebrospinal fluid. Direct injection of MSCs into damaged brain region followed by trepanation is frequently unreasonable due to additional surgical interventions. Authors chose technique of MSCs perineural migration in combined therapy of brain injuries and strokes with SCs [6-10]. Cranial nerves were chosen as the way for MSCs migration. Injection of MSCs into cranial nerves' endings in facial area is quite simple surgical procedure which guarantees MSCs migration to damaged brain regions [6-10].

Such manipulations were performed in line with approved by the Ministry of Health of the Republic of Belarus treatment protocols in 40 patients with ischemic and hemorrhagic strokes [12,13]. Only autologous MSCs were used [12,13]. Authors considered well known fact that MSCs actively move in the living organism to damaged tissue or organ. Such migration is triggered by multiple signaling molecules of protein and other nature which are expressed in damaged tissues. This observation is very promising for bioprinting technology [14]. Authors experimentally proved effectiveness of such technique on laboratory animals (Figure 1) when MSCs were injected into perineural space of vagus nerve at the level of thyroid cartilage leading to recovery of impaired heart functions $[15,16]$. The technique (Figure 1) was further developed and used for MSCs delivery from perineural space of vagus nerve to damaged areas in liver, pancreas, stomach and small intestine [17]. Such method of cell therapy guarantees targeted perineural migration of MSCs to certain damaged organ. Therefore, there is no more need of using major surgery to implement technique of MSCs migration.

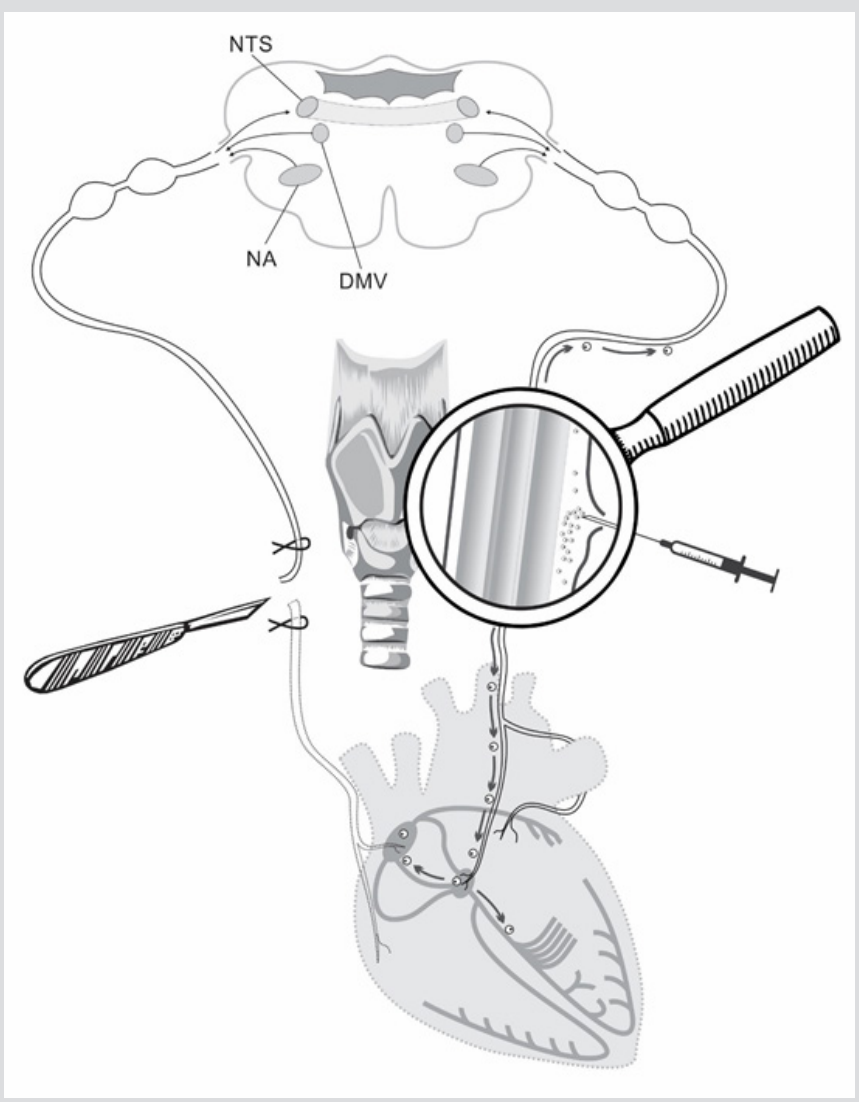

Figure 1: Scheme of perineural MSCs migration after unilateral vagotomy and perineural implantation of MSCs into intact vagus nerve on the other side. Arrows indicate MSCs migration. 


\section{Conclusion}

Obtained experimental data and clinical outcomes speak for technique of MSCs migration as promising method for activation of reparative processes in damaged areas of inner organs. Future development of combined cell therapy with standard treatment ways should consider using only autologous MSCs together with individual characteristics of patients and optimal way of MSCs perineural delivery to damaged area.

\section{Acknowledgement}

This pooled analysis was funded by 000 "Synergy", and by SSTP "New methods of medical care", section "Transplantation of cells, tissues and organs" (2016-2020).

\section{Conflict of Interest}

All listed authors concur with the submission of the manuscript; all authors have approved the final version. The authors have no financial or personal conflicts of interest.

\section{References}

1. Omotuyi AO (2017) New Delivery Systems of Stem Cells for Vascular Regeneration in Ischemia. Front Cardiovasc Med 4: 7.

2. Huang K, Hu S, Cheng K (2019) A New Era of Cardiac Cell Therapy: Opportunities and Challenges. Adv Healthc Mater 8(2): e1801011.

3. Silva LHA, Cruz FF, Morales MM, Weiss DJ, Rocco PRM (2017) Magnetic targeting as a strategy to enhance therapeutic effects of mesenchymal stromal cells. Stem Cell Res Ther 8(1): 58.

4. Cores J, Caranasos TG, Cheng K (2015) Magnetically Targeted Stem Cell Delivery for Regenerative Medicine. J Funct Biomater 6(3): 526-546.

5. Kerans FFA, LungaroL, Azfer A, Salter DM (2018) The Potential of Intrinsically Magnetic Mesenchymal Stem Cells for Tissue Engineering. Int J Mol Sci 19(10): 3159

\section{ISSN: 2574-1241}

DOI: 10.26717/BJSTR.2019.16.002830

Kulchitsky Vladimir. Biomed J Sci \& Tech Res

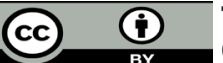

This work is licensed under Creative Commons Attribution 4.0 License

Submission Link: https://biomedres.us/submit-manuscript.php
6. Kulchitsky V, Zamaro A, Shanko Y, Koulchitsky S (2018) Prospects of Perineural Implantation of Stem Cells in Recovery of Neural Networks' Functions in Brain Diseases. Biomed J Sci\&Tech Res 10(3): 1-4.

7. Shanko Y, Zamaro A, Takalchik Stukach Y, Koulchitsky S, Pashkevich S, et al. (2018) Mechanisms of Neural Network Structures Recovery in Brain Trauma. Biomed J Sci\&Tech Res 7(5): 1-2

8. Kulchitsky V, Zamaro A, Navitskaya V, Koulchitsky S, Shanko Y (2018) Regulatory Effects of Mesenchymal Stem Cells in Brain. Biomed J Sci\&Tech Res 11(1): 1-3.

9. Kulchitsky V, Zamaro A, Navitskaya V, Shanko Y, Pashkevich S, et al (2018) Perspectives of stem cells use in Alzheimer's disease treatment. J Neurol Stroke 8(3): 190-191.

10. Kulchitsky V, Zamaro A, Shanko Y, Koulchitsky S (2018) Positive and negative aspects of cell technologies in cerebral diseases. J Neurol Stroke 8(2): 87-88.

11. Bradbury MWB (1992) Physiology and Pharmacology of the BloodBrain Barrier. Springer Verla, pp. 549.

12. Shanko Y, Navitskaya V, Zamaro A, Krivenko S, Zafranskaya M, et al. (2018) Prospects of Perineural Administration of Autologous Mesenchymal Stem Cells of Adipose Tissue in Patients with Cerebral Infarction. Biomed J Sci\&Tech Res 10(1): 1-3.

13. Shanko Y, Navitskaya V, Zamaro A, Zafranskaya M, Krivenko S, et al (2018) Somatotopic principle of perineural implantation of stem cells in patients with brain injuries. J Neurol Stroke 8(5): 259-261.

14. Zamaro A, Krivenchuk D, Denisov A, Koulchitsky S, Kulchitsky V (2018) Topical Issues of Bioprinting Technology. Biomed J Sci \& Tech Res 12(1) $1-3$

15. Zamaro A, Koulchitsky S, Pashkevich S, Stukach Y, Dosina M, et al. (2019) Perineural Way of Stem Cells Migration to Injured Heart Regions. Biomed J Sci \& Tech Res 14(1): 1-4.

16. Kulchitsky V, Zamaro A, Koulchitsky S (2019) Perineural Migration of Stem Cells in the Model of Damaged Heart Nodes. Biomed J Sci \& Tech Res 14(4): 1-3.

17. Kulchitsky V, Zamaro A, Krivenchuk D Koulchitsky S (2019) Can Nerve Trunks Serve as Railroads for Stem Cells? Biomed J Sci \& Tech Res 15(1): $1-4$.

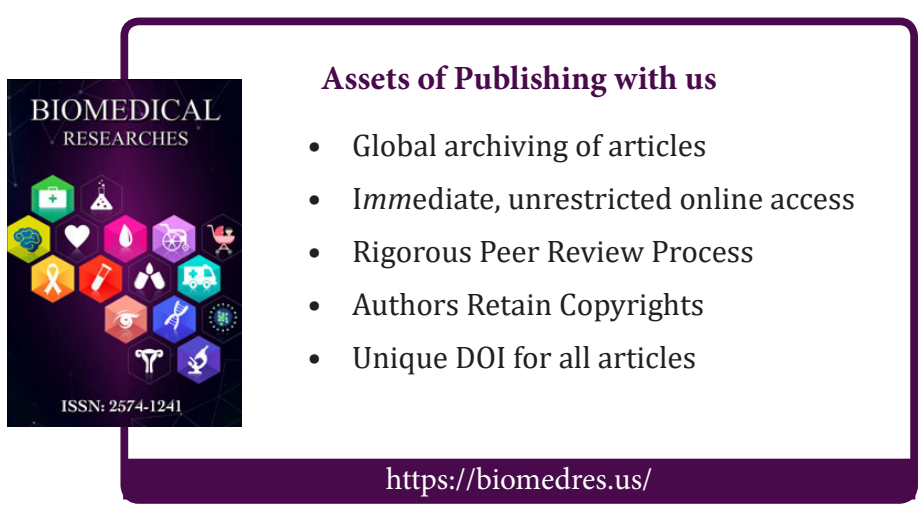

